\title{
Cloning and characterization of a gene (LIP1) which encodes a lipase from the pathogenic yeast Candida albicans
}

\author{
Yue Fu, ${ }^{1}$ Ashraf S. Ibrahim, ${ }^{1}$ William Fonzi, ${ }^{2}$ Xiang Zhou, ${ }^{1}$ \\ Clarisa F. Ramos ${ }^{1}$ and Mahmoud A. Ghannoum ${ }^{3}$
}

Author for correspondence: Mahmoud A. Ghannoum. Tel: +1216844 8580. Fax: +12168441076. e-mail: MAG3@PO.CWRU.EDU

1 Division of Infectious Diseases, St John's

Cardiovascular Research Center, Department of Medicine, Harbour-UCLA Medical Center, Torrance, CA 90509, USA

2 Department of Microbiology and Immunology, School of Medicine, Georgetown University Medical Center, Washington, DC 20007-2197, USA

3 University Center for Medical Mycology, and Mycology Reference Laboratory, Department of Dermatology, Case Western Reserve University and University Hospitals of Cleveland, 11100 Euclid Avenue, Stop LKS 5028, Cleveland, OH 44106-5028, USA

\begin{abstract}
Extracellular phospholipases are demonstrated virulence factors for a number of pathogenic microbes. The opportunistic pathogen Candida albicans is known to secrete phospholipases and these have been correlated with strain virulence. In an attempt to clone $C$. albicans genes encoding secreted phospholipases, Saccharomyces cerevisiae was transformed with a C. albicans genomic library and screened for lipolytic activity on egg-yolk agar plates, a traditional screen for phospholipase activity. Two identical clones were obtained which exhibited lipolytic activity. Nucleotide sequence analysis identified an ORF encoding a protein of 351 amino acid residues. Although no extensive homologies were identified, the sequence contained the Gly-X-Ser-XGly motif found in prokaryotic and eukaryotic lipases, suggesting a similar activity for the encoded protein. Indeed, culture supernatants from complemented yeast cells contained abundant hydrolytic activity against a triglyceride substrate and had no phospholipase activity. The data suggest that C. albicans, in addition to phospholipases, also has lipases. Southern blot analyses revealed that C. albicans may contain a lipase gene (LIP) family, and that a lipase gene(s) may be present in Candida parapsilosis, Candida tropicalis and Candida krusei, but not in Candida pseudotropicalis, Candida glabrata or $S$. cerevisiae. Northern blot analyses showed that expression of the LIP1 transcript, the cloned gene which encodes a lipase, was detected only when $C$. albicans was grown in media containing Tween 80 , other Tweens or triglycerides as the sole carbon source, and not in Sabouraud Dextrose Broth or yeast/peptone/dextrose media. Additionally, carbohydrate supplementation inhibited LIP1 expression. Cloning this gene will allow the construction of LIP1deficient null mutants which will be critical in determining the role of this gene in candidal virulence.
\end{abstract}

Keywords: Candida albicans, LIP1, lipase

\section{INTRODUCTION}

Pathogenic fungi, including Candida albicans, are known to secrete various hydrolytic enzymes such as proteinases, phospholipases and lipases (Ogawa et al., 1992). These extracellular hydrolytic enzymes may contribute to pathogenesis of infections by disrupting host cell membranes and extracellular matrices, thus aiding in dissemination and tissue invasion (Salyers \&

The GenBank accession number for the sequence reported in this paper is U34807.
Whitt, 1994). These enzymes may also allow microorganisms to utilize host cell macromolecules as a source of nutrients (Salyers \& Whitt, 1994). C. albicans enzymes considered to be integral to pathogenesis are categorized into two main types: (1) proteinases that hydrolyse peptide bonds, and (2) phospholipases which hydrolyse phospholipids. The aspartyl proteinases have been extensively studied (for review see Ghannoum $e t$ al., 1995; White \& Agabian, 1995).

Experimental evidence implicating phospholipase as a virulence factor of C. albicans exists (Barrett-Bee $e$ t al., 1985; Ibrahim et al., 1995). Barrett-Bee et al. (1985) 
found that isolates of $C$. albicans with the highest extracellular phospholipase activity adhered most strongly to buccal epithelial cells and were most pathogenic in mice. In a recent study, our group obtained evidence that strongly suggests that extracellular phospholipases of C. albicans contribute to virulence of this yeast (Ibrahim et al., 1995). Cloning of a gene(s) encoding extracellular candidal phospholipases is the essential first step to answer more definitively whether extracellular phospholipases contribute to the pathogenesis of C. albicans.

In this study, in an attempt to clone candidal extracellular phospholipases, we utilized a complementation strategy employing a lipase-deficient strain of Saccharomyces cerevisiae transformed with a C. albicans genomic library. The transformed organisms were screened for lipolytic activity using egg-yolk agar media. The egg-yolk agar assay has been used conventionally for the rapid screening of clinical isolates of C. albicans for the production of phospholipase (Price et al., 1982; Williamson et al., 1986). In this assay, phospholipase-producing strains are identified by the formation of a zone of turbidity around the colony. We have cloned and sequenced a C. albicans gene that imparted a positive response to $S$. cerevisiae cells grown on egg-yolk agar. Interestingly, nucleotide sequence analysis, and substrate specificity studies, utilizing specific phospholipid and triglyceride substrates, revealed that the cloned gene encodes a lipase and not a phospholipase. Although studies directed at investigating fungal lipases centre around their industrial applications, little attention has been paid to the contribution of lipases to fungal pathogenesis. Cloning a candidal gene encoding a lipase will allow determination of its role in the virulence of this important nosocomial pathogen. In this study, we have cloned and characterized a lipase gene (LIP1) from a clinical isolate of C. albicans. Additionally, Southern and Northern blot analyses were performed to search for the presence of homologous sequences in other albicans and nonalbicans species, as well as to determine the level of expression of the LIP1 gene.

\section{METHODS}

Strains and growth conditions. Candida albicans ATCC 36082 (a clinical isolate) and Candida cylindracea ATCC 14830 were obtained from the American Type Culture Collection. Saccharomyces cerevisiae strain LL-20, a lipasedeficient strain (MAT a leu2-3,112 his3-11,15 can1), was from William Fonzi (Georgetown University). Escherichia coli strain XL1-Blue was purchased from Stratagene. The following clinical albicans and non-albicans strains were used in this study to determine the universal distribution of the LIP1 gene: C. albicans (six isolates), Candida parapsilosis (three isolates), Candida tropicalis (two isolates) and one isolate of Candida krusei, Candida pseudotropicalis and Candida glabrata.

Yeast cells of C. albicans were routinely grown at $30^{\circ} \mathrm{C}$ in YPD medium $(1 \%, \mathrm{w} / \mathrm{v}$, yeast extract; $2 \%, \mathrm{w} / \mathrm{v}$, peptone; $2 \%, w / v$, dextrose; Difco). The medium used for selecting $S$. cerevisiae transformants was Yeast Nitrogen Base without amino acids or ammonium sulfate (YNB; Difco) supplemented with $2 \%(\mathrm{w} / \mathrm{v})$ dextrose, $0.5 \%(\mathrm{w} / \mathrm{v})$ ammonium sulfate and $100 \mu \mathrm{g} \mathrm{L}$-leucine $\mathrm{ml}^{-1}$ (Sigma). Egg-yolk medium used to detect lipolytic activity consisted of (in $184 \mathrm{ml}$ distilled water): Sabouraud Dextrose Agar (Difco), $13.0 \mathrm{~g} ; \mathrm{NaCl}$, $11.7 \mathrm{~g} ; \mathrm{CaCl}_{2}, 0 \cdot 111 \mathrm{~g}$; and $10 \%(\mathrm{v} / \mathrm{v})$ sterile egg yolk. The egg yolk was aspirated from the chicken eggs and centrifuged at $500 \mathrm{~g}$ for $10 \mathrm{~min}$ at room temperature to remove particulate matter. Twenty millilitres of the supernatant was added to the sterilized medium. Luria-Bertani (LB), SOB and SOC media used for growth of $E$. coli were prepared as described by Sambrook et al. (1989). Ampicillin (final concentration $80 \mu \mathrm{g}$ $\mathrm{ml}^{-1}$ ) was added as required. All media were solidified with $1.5 \%$ agar (Difco).

To study the expression of the LIP1 gene by Northern analyses, fungi were grown in rich (Sabouraud Dextrose Broth and YPD) and chemically defined [YNB and Lee's (1975)] media under different growth conditions. Compounds used to supplement YNB included: Tweens 20, 40, 60 and 80, carbohydrate (glucose, maltose and galactose), phosphatidylcholine and $\alpha$-naphthyl palmitate; these were purchased from Sigma. The triglycerides used in supplementing YNB were obtained from egg-yolk lipids and purified by TLC as described previously by Ghannoum et al. (1986b).

Plasmids and transformations. Two E. coli-S. cerevisiae

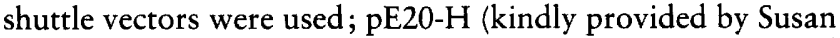
Sandmeyer, University of California at Irvine), a $2 \mu$-based multicopy yeast plasmid containing the selectable HIS 3 gene, and pRS415 (Stratagene), a single-copy, centromere-based cloning vector. The sequencing plasmid used was pBluescript $\mathrm{SK}(+)$ (Stratagene). E. coli transformation was carried out according to the method of Hanahan (1983). Transformation of $S$. cerevisiae was performed using the protocol of Schiestl \& Gietz (1989).

Genomic library construction. For genomic DNA isolation, $C$. albicans ATCC 36082 was grown to stationary phase in YPD medium. Genomic DNA was extracted by the method of Scherer \& Stevens (1988), and partially digested with Sau3AI (Boehringer Mannheim). DNA fragments $10-15 \mathrm{~kb}$ in length were isolated by sucrose gradient centrifugation (Sambrook et al., 1989) and then ligated into the BamHI site of pE20-H. Analysis of random transformants indicated that $75 \%$ of the plasmids contained inserts of $10-15 \mathrm{~kb}$. The resultant DNA library of about 8000 clones was amplified in E. coli strain XL1-Blue, and subsequently transformed into $S$. cerevisiae strain LL-20 to yield 24000 transformants.

Since the C. albicans LEU2 gene is known to complement the leu2 mutation of $S$. cerevisiae (Jenkinson et al., 1988), the frequency of $\mathrm{Leu}^{+}$transformants was determined to provide an indication of the completeness of the library and the frequency of single-copy genes within the library. By this test, $1 / 2200 \mathrm{~S}$. cerevisiae transformants was $\mathrm{Leu}^{+}$, indicating that the library was representative and contained a high frequency of inserts.

RNA isolation. Fungal cells from various growth conditions were harvested by centrifugation for $5 \mathrm{~min}$ at $3000 \mathrm{~g}$ at $4{ }^{\circ} \mathrm{C}$ and the pellet was frozen in an ethanol/dry-ice bath precooled to $-20^{\circ} \mathrm{C}$. The cells were resuspended in $1.5 \mathrm{ml}$ phenol, $1.5 \mathrm{ml} \mathrm{TE}$ buffer ( $10 \mathrm{mM}$ Tris/ $\mathrm{HCl}, \mathrm{pH} 7 \cdot 6,1 \mathrm{mM}$ EDTA), containing $6 \mathrm{~g}$ glass beads and $75 \mu \mathrm{l} 10 \% \mathrm{SDS}$, and vortexed for $4 \mathrm{~min}$. Following centrifugation for $10 \mathrm{~min}$ at $3000 \mathrm{~g}$, the aqueous phase was extracted three times with phenol (saturated with Tris buffer and $0.1 \% 8$-hydroxyquinoline) and once with phenol/chloroform. The RNA was then precipitated with 0.1 vol. $3 \mathrm{M} \mathrm{NaOAc} / \mathrm{HOAc}(\mathrm{pH} \mathrm{5.2)}$ ) and two vols 
$100 \%$ ethanol, and stored at $-20^{\circ} \mathrm{C}$. Precipitated RNA was pelleted and resuspended in $200 \mu$ l diethyl-pyrocarbonatetreated $\mathrm{H}_{2} \mathrm{O}$

Southern (DNA) and Northern (RNA) blot analysis. Standard DNA electrophoretic techniques and formaldehyde RNA gels were performed according to the methods outlined by Sambrook et al. (1989). Blotting was carried out with nylon membranes (MSI) as described in the manufacturer's instructions. DNA fragments $(1 \cdot 1 \mathrm{~kb})$, representing the lipase gene, used as hybridization probes were extracted from gels with the Gene-Clean kit (Bio101) and labelled with $[\alpha$ ${ }^{32}$ P]dATP, total count of $4 \times 10^{7}$ c.p.m., by using an NEBlot kit (New England Biolabs). DNA containing the C. albicans actin gene was used as a control in Northern analysis. Additionally, Southern blot analyses were used in other experiments to determine whether homologous sequences are present in clinical isolates of albicans and non-albicans species. Northern blot analyses were performed to monitor the expression of this gene in these isolates.

For low-stringency hybridization, genomic DNA was bound to nylon membranes. The membranes were then prehybridized at $42{ }^{\circ} \mathrm{C}$ for $60 \mathrm{~min}$ in a solution containing $5 \times$ SSPE, $5 \times$ Denhardt's, $20 \%$ formamide (Fisher Biotech), 1\% SDS and $100 \mu \mathrm{g}$ denatured salmon-sperm DNA ml $\mathrm{m}^{-1}$. Hybridization was performed in the same solution containing the ${ }^{32} \mathrm{P}$ labelled DNA probe. The membranes were exposed to X-ray film after three washes in $0.2 \times$ SSC, $0.1 \%$ SDS at $42^{\circ} \mathrm{C}$. Similar conditions were used for high-stringency hybridization with the exception that the formamide concentration was changed from 20 to $50 \%$. Hybridization was performed overnight in the same solution containing the ${ }^{32} \mathrm{P}$-labelled random primed probe. The membranes were exposed to Xray film after three washes in $0.2 \times$ SSC and $0.1 \%$ SDS at $42^{\circ} \mathrm{C}$.

Selection and confirmation of clones exhibiting lipolytic activity. To screen for clones having lipolytic activity, transformants of $S$. cerevisiae LL-20 were spread on egg-yolk agar medium and incubated at $30^{\circ} \mathrm{C}$ for $96 \mathrm{~h}$. Clones displaying lipolytic activity were identified by colonies surrounded by a halo of precipitation.

Sequencing. A $2.5 \mathrm{~kb}$ Xhol-Pst I DNA fragment containing the putative lipase gene was cloned into plasmid pBluescript $\mathrm{SK}(+)$ in both orientations and unidirectional deletion constructs were generated by ExoIII digestion (Henikoff, 1984). The DNA sequence was determined, in both directions, using the dideoxy chain-termination method and the entire sequence was determined from both strands (Sanger et al., 1977). Nucleotide and protein sequence analyses were performed with the Wisconsin Genetics Computer Group sequence analysis software package, version 7.0 (Devereux et al., 1984). Homology searches of the GenBank database were conducted with the FASTA program (Pearson \& Lipman, 1988).

Functional analysis of the cloned enzyme. To determine the functional activity of the encoded enzyme, transformed $S$. cerevisiae cells were grown for $24 \mathrm{~h}$ in $500 \mathrm{ml}$ Sabouraud Dextrose Broth (Difco) at $30^{\circ} \mathrm{C}$ and then centrifuged at $4{ }^{\circ} \mathrm{C}$ to remove particulate material. The supernatants were then collected and concentrated, about 10 -fold, by ultrafiltration using Minitan-S filter sheets, 10000 NMWL (Millipore), and stored at $-70^{\circ} \mathrm{C}$. The activity of the encoded enzyme was determined by a radiometric assay (Ibrahim et al., 1995). The lipase activity was assayed using triolein $\left[9,10{ }^{3} \mathrm{H}(\mathrm{N})\right]$ [specific activity $18.4 \mathrm{Ci} \mathrm{mmol}^{-1}\left(680 \mathrm{GBq} \mathrm{mmol}^{-1}\right)$; DuPont NEN] as the substrate, while phospholipase activity was assayed using L-3-phosphatidylcholine, $\quad 1$-palmitoyl-2[1-14 C]palmitoyl [specific activity $157 \mathrm{mCi} \mathrm{mmol}^{-1}\left(5.8 \mathrm{GBq} \mathrm{mmol}^{-1}\right)$; DuPont NEN] as the substrate. To determine lysophospholipase activity, the substrate was L-lyso-3-phosphatidylcholine, 1-[1${ }^{14} \mathrm{C}$ ]palmitoyl [specific activity $56.7 \mathrm{mCi} \mathrm{mmol}^{-1}(2 \cdot 1 \mathrm{GBq}$ $\mathrm{mmol}^{-1}$ ); DuPont NEN].

An equal volume of the concentrated supernatant was added to $0.25 \mathrm{ml} \mathrm{0.1} \mathrm{M}$ citrate buffer $(\mathrm{pH} 4.0)$ containing $0.1 \%(\mathrm{v} / \mathrm{v})$ Triton $\mathrm{X}-100$ and $48 \mathrm{nmol}$ radiolabelled substrate. The mixture was incubated for $20 \mathrm{~min}$ at $37^{\circ} \mathrm{C}$. The reaction was stopped by adding $2 \mathrm{ml}$ chloroform/methanol $(2: 1, \mathrm{v} / \mathrm{v})$ and the samples were extracted as described previously by Ibrahim et al. (1995). After drying under nitrogen, the lipid-containing phase was suspended in $0 \cdot 1 \mathrm{ml}$ chloroform and fractionated by TLC using a non-polar solvent system (Ghannoum et al., 1986a). The lipids were visualized using iodine vapour and the bands were scraped from the plate into scintillation vials. The amount of radioactivity in each band was determined by scintillation spectroscopy and the results were expressed as a percentage of the total radioactivity in each lane. Authentic standards were chromatographed in parallel to determine the identity of the lipid fractions. All samples were tested in duplicate.

Verification that the egg-yolk assay can detect both phospholipase and lipase activities. For the egg-yolk assay to detect phospholipase and lipase activities it should contain the appropriate substrates (phospholipids and triglycerides, respectively). To demonstrate that egg yolk contains these substrates we obtained the egg yolk from one egg and extracted the lipids by suspending the yolk in chloroform/ methanol $(2: 1, \mathrm{v} / \mathrm{v})$. Total lipids were purified by established procedures (Folch et al., 1957). The purified lipids were fractionated into individual phospholipids and neutral lipids by TLC as described previously (Ghannoum et al., 1986b). Individual components were identified by comparison of their $R_{F}$ mobility with those of commercially available standards.

\section{RESULTS}

\section{Isolation of clones encoding C. albicans lipid- hydrolysing enzymes}

To clone candidal genes encoding phospholipases it was necessary to use a screening method that is rapid, cheap and can resolve the enzyme activity in a large number of clones. The egg-yolk agar assay has been traditionally used for the rapid screening of clinical isolates of $C$. albicans for the production of extracellular phospholipase activity. In this assay, phospholipase-producing strains are identified by the formation of a zone of turbidity around the colony. Although some strains of $S$. cerevisiae produce extracellular phospholipase (Lee et al., 1994), preliminary experiments showed that strain LL-20, unlike C. albicans, did not form a zone of turbidity in this assay, and, therefore, did not secrete detectable phospholipases. This finding suggested that the egg-yolk assay could be useful in cloning phospholipase genes from C. albicans by the ability of Candida DNA sequences to complement the $S$. cerevisiae LL-20 strain.

To screen for clones exhibiting lipolytic activity, approximately $2 \times 10^{4} \mathrm{~S}$. cerevisiae transformants, con- 


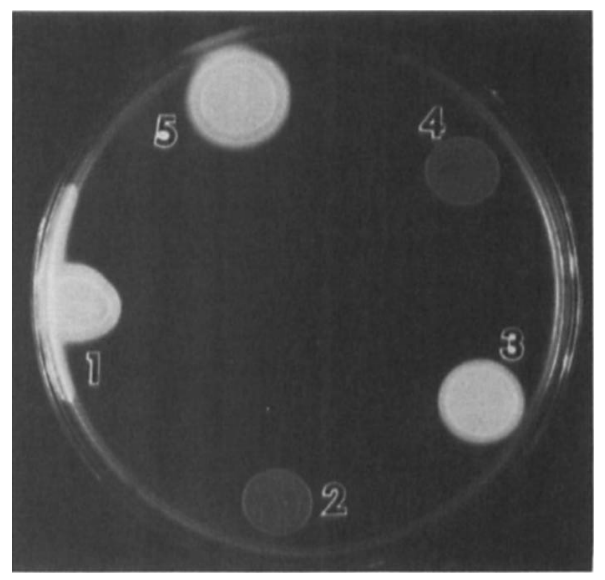

Fig. 1. Egg-yolk plate assay for detecting lipolytic activity. 1 and 3,5 . cerevisiae LL-20 transformed with candidal DNA expressing lipolytic activity; 2 , S. cerevisiae LL-20 transformed with the parent plasmid pE20-H showing no lipolytic activity; 4, $S$. cerevisiae LL-20 with no plasmid exhibiting no activity; $5, C$. albicans ATCC 36082 secreting lipid-hydrolysing enzymes.

taining 10-15 kb candidal DNA fragments, were spread on egg-yolk agar medium. In this initial screen, two colonies positive for lipolytic activity were identified. Both isolates were $\mathrm{Leu}^{-} \mathrm{His}^{+}$, suggesting that they were derived from the original $S$. cerevisiae strain and were not contaminant C. albicans. Plasmid DNA was recovered from the two positive clones and used to transform E. coli strain XL1-Blue. To verify that the plasmids encoded the hydrolytic activity, $S$. cerevisiae LL-20 was transformed with the purified plasmids and screened again for activity on egg-yolk agar. S. cerevisiae containing the parent plasmid $\mathrm{pE} 20-\mathrm{H}$ was used as a negative control. Six isolates from each transformation were tested on egg-yolk agar. Each of the transformants was observed to possess lipolytic activity, while cells containing the parent plasmid $\mathrm{pE} 20-\mathrm{H}$ were negative in that they did not show any lipolytic activity (Fig. 1).

The LIP1 gene was localized by subcloning portions of the insert DNA into pE20-H and subsequently screening the $S$. cerevisiae LL-20 transformants for lipolytic activity. Restriction mapping of the recovered plasmids indicated that each contained a common insert of approximately $9 \mathrm{~kb}$. By this method, the gene was localized to a $2.3 \mathrm{~kb}$ Xhol-PstI fragment (Fig. 2a).

Prior to subcloning and sequence analysis of the LIP1 gene, the cloned DNA was hybridized to C. albicans genomic DNA to verify that the cloned fragment was derived from this organism. Furthermore, the cloned DNA fragment was able to hybridize only to sequences present in C. albicans genomic DNA and not to those present in S. cerevisiae (data not shown), confirming that the cloned gene is of candidal origin. In addition, Southern blot analysis of candidal genomic DNA digested with a number of restriction endonucleases was performed and demonstrated colinearity between the cloned DNA fragment and the genome.
Nucleotide sequence determination of the cloned gene

The nucleotide sequence was determined for a $2053 \mathrm{bp}$ region of the complementing $2.3 \mathrm{~kb}$ XhoI-Pst fragment (Fig. 2a). Analysis of this sequence revealed a single 1053 bp ORF encoding a putative peptide 351 amino acids in length with a predicted molecular mass of $38 \mathrm{kDa}$ (Fig. $2 \mathrm{~b})$. The predicted protein had a hydrophobic amino terminus, suggesting that the protein may be secreted, but no obvious signal peptide cleavage site (von Heijne, 1986). MacPattern analysis for Prosite motifs (Fuchs, 1994) found $N$-glycosylation sites at amino acid positions 114, 202, 300, 305 and 334 .

BLAST (Altschul et al., 1990) and BLocks (Henikoff \& Henikoff, 1991) homology searches found no significant homology to known proteins. However, it was noted that the putative protein contained a Gly-X-Ser-X-Gly motif characteristic of lipases (Antonian, 1988). The significance of this motif was investigated by multiple sequence alignment using Gibb's sampling strategy (Lawrence et al., 1993) as instituted by the program MACAW (Schuler et al., 1991). A significant block of homology $\left(P \sim 0, N=1.491 \times 10^{40}\right)$ which encompassed amino acids Ala-71 to Ser-82 of the C. albicans protein was identified when compared with 14 lipases of fungal and mammalian origin (data not shown). This block contains the Gly-X-Ser-X-Gly motif. When compared to fungal lipases only, an extended block of homology $(P$ $\sim 0, \mathrm{~N}=3.347 \times 10^{13}$ ) was identified between amino acids Pro-21 and Leu-108 (Fig. 3). A second extended region of homology was identified by visual alignment. This region, between Ala-121 and Asp-231 of the C. albicans gene, encompassed the Ser-His-Glu catalytic triad of the Geotrichum candidum lipase (Schrag et al., 1991). A corresponding histidine was present in the Candida gene, but the glutamic acid was not. However, the position of the catalytic acid residue varies in lipases (Schrag et al., 1992). Although the overall identity is small, $21 \%$, the extended regions of conservation and preservation of potential active site residues suggested that the C. albicans gene encodes a lipase.

\section{Gene dosage effects}

Because extensive structural homologies were not found, to confirm that the cloned lipase gene is a structural gene and not a regulatory gene which activates expression of an $S$. cerevisiae lipase, we cloned the functional DNA fragment into a single-copy (pRS315) as well as a multicopy $(\mathrm{pE} 20-\mathrm{H})$ vector. These constructs were then introduced into the $S$. cerevisiae LL-20 strain and assayed for their lipolytic activities. The yeast transformed with the multicopy vector expressed significantly higher lipolytic activity compared with the single-copy vector $(\mathrm{Pz}$ values of 0.92 and 0.58 for the single-copy and multicopy vectors, respectively). This zone $(\mathrm{Pz})$ is calculated by dividing the colony diameter by the diameter of the cloudy zone plus colony diameter and is used to quantify the lipolytic activity. Since higher copies of the gene resulted in greater lipolytic activity, 
(a)

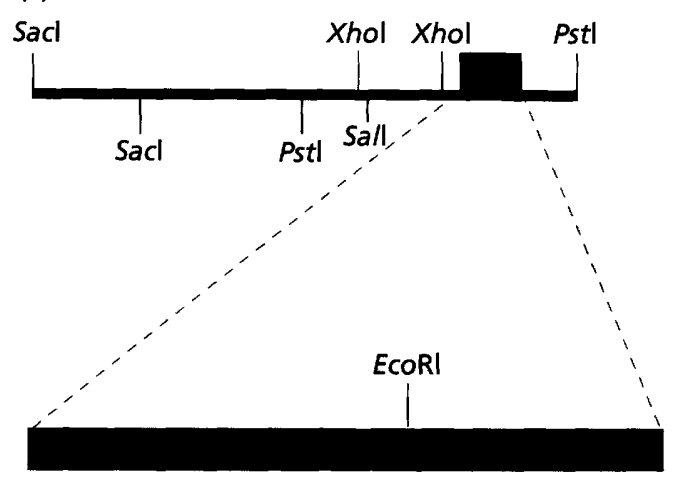

$1 \mathrm{~kb}$

$100 \mathrm{bp}$

(b)

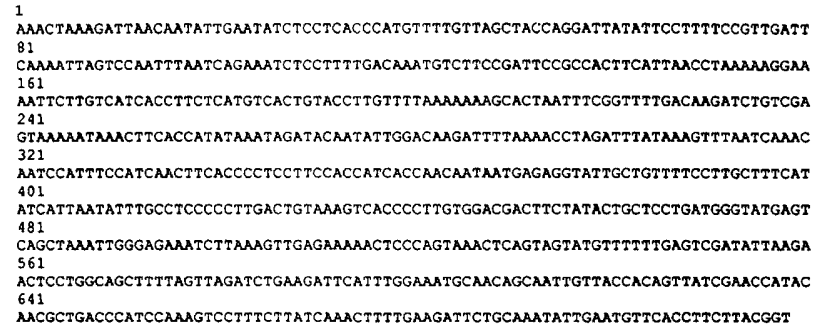

$719 / 1$
ATG CAA TAT GGT GCC CCT TGG TCA ACT GTG GCT ACT ATG CAA TAT GGT GCC CCT TGG TCA ACT GTG GCT ACT CAA ATT GAT ATG GCT TTA ATG GTA
Met gln tyr gly ala pro tep ser thr val ala thr gln ile asp met ala leu met val CCT ATG TTG AAG CAA GGT TAT TAC GTT GTC AGT CCT GAT TAT GAG GGA CCA AAA TCC ACA pro met leu lys gln gly tyr tyr val val ser pro asp tyr glu gly pro lys ser thr
$839 / 41$ GG phe thr val gly arg gln ser gly lys ala thr leu asp ser lle arg alo 1lo leu lys

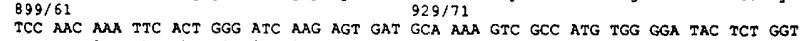
ser asn lys phe thr gly ile lys ser asp ala lys val sla met trp gly tyr ser gly GGT TCA TTA GCT TCT GGT TGG GCT GCT GCA TTA CMA CCT AAG TAT GCT CCA GAA TTG A gly ser leu ala ser gly trp ala ala ala leu gln pro lyg tyr ala pro glu leu lys 1019/101 AAA AAT ATT GGT GCT GCC CTT GGT GGG 2049/111 GTC ACT AAT ATT ACT GCC ACT GCC GAA AAA AAT TTG ATT GGT GCT GCC CTT GGT GGG TTT GTC ACT AAT ATT ACT GCC ACT GCC GAA
lys asn leu ile gly ala ala leu gly gly phe val thr agn 1le thr ala thr ala glu de

CCA ART GCC TTG AGT GGG TTA GCT AAT ald thr asp gly thr leu phe ala gly leu val pro asn ala leu ser giy leu ala asn GAG TAT CCC GAA TTC AAA GAA ATA CTT TAC CAA AAA GTC TCC AAA GCT GCT ACT GAC AAT. glu tyr pro glu phe lys glu íe leu tyr gln lys val ser lys ala ala thr asp asn $1199 / 161$

GAT GAC CAA Gly ale leu tyz phe ala glu asp gln TAC TTC ACT GGC GAT GAT AGA GCT TTC CCT GGA GGT TAT GGA TTA CTT AAA GAA GAG GTG ThC TTC ACT GGC GAT GAT AGA GCT TTC CCT GGA GGT TAT GGA TTA CTT AAA GAA GAG GTG
tyr phe thr gly asp asp arg ala phe pro gly gly tyr gly leu leu lys glu glu val
$1319 / 0.040$ GTG AAC AAG ACT ATT CTG GAA AAC AAT TTG ATG CAA ATG GAT AAA GAT TAT TTA CCA GAT GTG AAC AAG ACT ATT CTG GAA AAC AAT TTG ATG CAA ATG GAT AAA GAT TAT TTA CCA GAT
val asn lys thr ile leu glu asn asn leu met gin met asp 2 ys asp tyr leu pro asp val asn lys thr ile leu glu asn asn leu met gln met asp lys asp tyr leu pro asp ATI CCA ATT TTT GTA TAC CAT GGT GCA TTG GAT TCC ATT GTT CCA ATC AGT AAC GTC CAT
ile pro ile phe val tyr his GlY ala leu asp ser ile val pro ile ser asn val his 1le pro ile phe val tyr his gly ala leu asp ser ile val pro ile ser asn val his GTC ACT TAT AAR AAT TGG TGT GAT TGG GGG ATC AAC TCA TTT GAA TTT TCT GAG GAT TTA

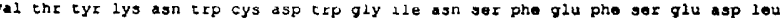

$1499 / 261$

TTA AAT GGC CAT ATC ACC GAA ACT ATT GTT GGG GCC CCG GCA GCT ATA ACA TGG TTA GAA leu asn gly his ile thr glu thr ile val gly ala pro ala ala ile thr trp leu glu GCA AGA TTT GAC GGT GAA CCA GTC GTC AAG GGA TGC AAA AAG ACT TCC AGA ATC ACC AAC

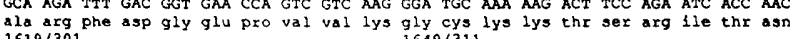
1619/301

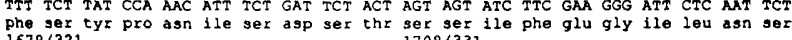
$1679 / 321$ 1709/331 GTT ACT GGT TCC GAA TTG GGT CCA GGT GTC ACC TCT GAT AAC ATA ACG TTG GAT GGA TTA
val thr gly sex glu leu gly pro gly val thr sex asp asn ile thr leu asp gly leu 27CC GGA TTC TTG GGG AAC TTT ATT GAC TTA $1769 / 351$ AAA TAG ATGACAAACAAGAAAAAMAAAAAAACCCTAC

3006

TTACAGCCAMACCTAATCATATCCACCACCTACAAATTTATTTATTTTCGTTGCCCTTTTTCAATTTCTTTACATACCA 1886

AATTCTMCTTTAAMGGTGATTTAATTTTAAATACATATATACAAGTTAACTTACCATAAAC2MACATTTCTATMAAM

TCCAACGTTGGATTCTCTCCTGTTTITGTAGTGGTTATGTCGGTGTCAGCCCACTGTTCGAGGAAATCATGGTGCGATTC 2046

Fig. 2. (a) Restriction map of the $2 \cdot 3 \mathrm{~kb}$ Xhol-Pstl genomic DNA fragment containing the LIPI gene. The boxed area in the lower portion of the figure indicates the fragment encoding the ORF of the LIP1 gene. (b) Nucleotide sequence of the complementing DNA fragment and predicted amino acid sequence of the putative ORF. The numbers refer to the nucleic

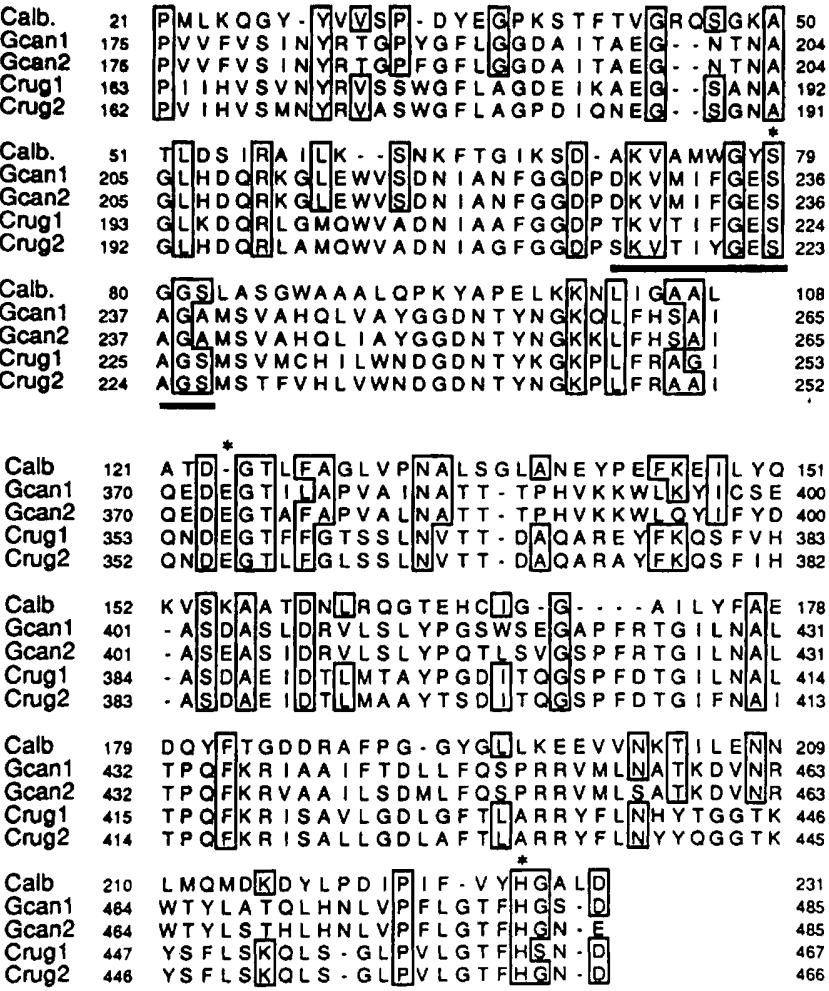

Fig. 3. Multiple sequence alignment of $C$. albicans putative lipase with lipases from $G$. candidum and $C$. cylindracea (rugosa). Catalytic residues are marked with asterisks. The region conserved in fungal mammalian lipases is underlined. The boxed regions in the figure contain identical amino acid residues.

the results are consistent with the cloned C. albicans gene encoding this activity.

\section{Functional analysis of the enzyme encoded by the candidal gene}

During the initial isolation of this gene, we used eggyolk agar which has been the traditional screen for phospholipase activity (Samaranayake et al., 1984; Schuler et al., 1991). However, there are substantial amounts of triglycerides in the egg yolk, suggesting lipase activity might also be detected (see below). Because the cloned gene lacked detectable homology with known phospholipases, but exhibited some similarity to lipases, we developed a more specific assay to determine if the candidal enzyme was a phospholipase or a lipase.

To examine the type of enzyme activity encoded by the candidal gene, the concentrated supernatants from cultures of transformed $S$. cerevisiae were assayed for

acid/amino acid residues. The numbers specifying the nucleic acid residues are derived from the entire genomic fragment sequenced, whereas the amino acid numbers refer to the first methionine defining the coding region of the LIP1 gene. 
Table 1. Enzymic activity of the encoded protein

Values are the mean \pm SD of analyses of three separate experiments. ND, No detectable activity.

\begin{tabular}{|lccc|}
\hline Strain & \multicolumn{3}{c|}{ Activity [units (mg protein) ${ }^{-1}$ ] } \\
\cline { 2 - 4 } & Phospholipase $^{*}$ & Lysophospholipase $\dagger$ & Lipase $\neq$ \\
\hline S. cerevisiae (Candida gene) & ND & ND & $10 \cdot 84 \pm 0 \cdot 14$ \\
S. cerevisiae (empty plasmid) & ND & ND & ND \\
C. cylindracea $\$$ & ND & $104 \cdot 9 \pm 2 \cdot 3$ & $14.04 \pm 3.96$ \\
Purified phospholipase standard $\|$ & $4 \cdot 7 \pm 0.34$ & FCSnd & ND \\
\hline
\end{tabular}

*Unit is defined as the activity of the enzyme required to liberate $0.1 \mathrm{nmol}$ fatty acid from phosphatidylcholine $\mathrm{ml}^{-1} \mathrm{~h}^{-1}$.

†Unit is defined as the activity of the enzyme required to liberate $0 \cdot 1 \mathrm{nmol}$ fatty acid from lysophosphatidylcholine $\mathrm{ml}^{-1} \mathrm{~h}^{-1}$.

$\ddagger$ Unit is defined as the activity of the enzyme required to liberate $0.01 \mathrm{nmol}$ fatty acid from trioline $\mathrm{ml}^{-1}$ $\mathrm{h}^{-1}$.

$\$$ Positive control of lipase activity.

|| Positive control of phospholipase activity.

(a)

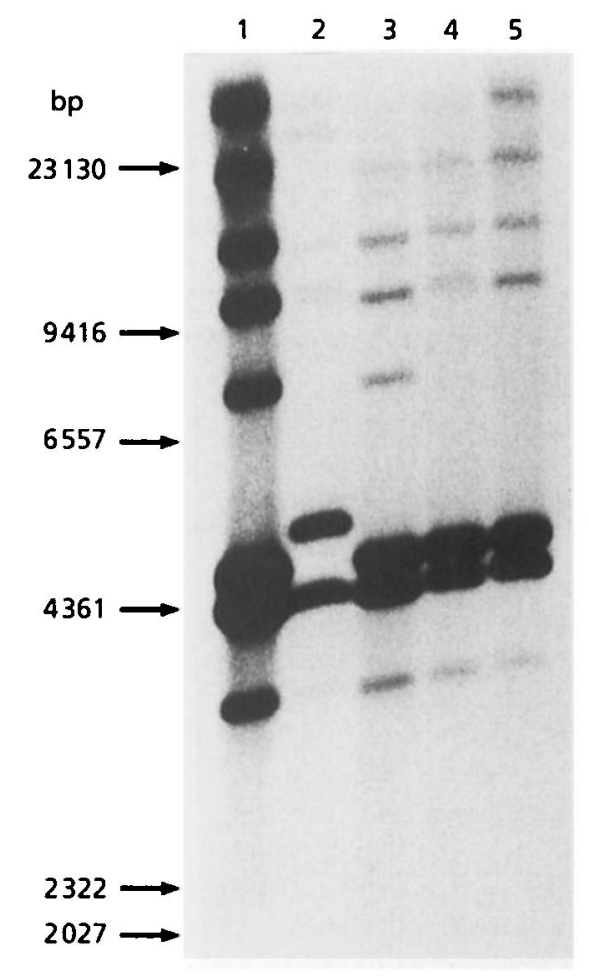

(b)

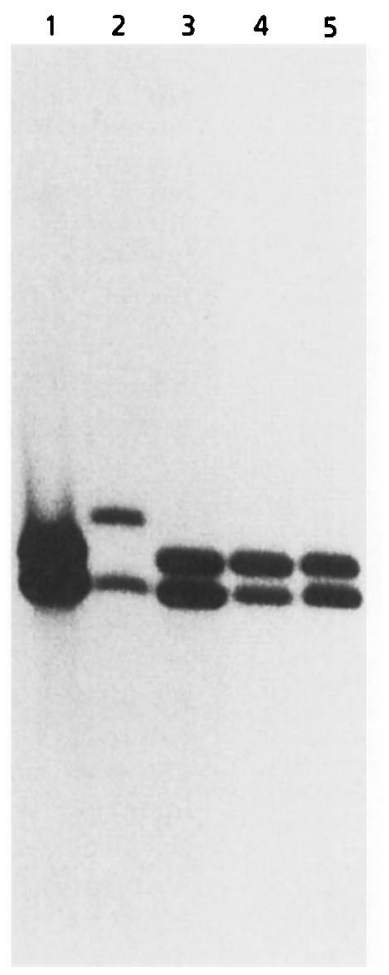

(c)

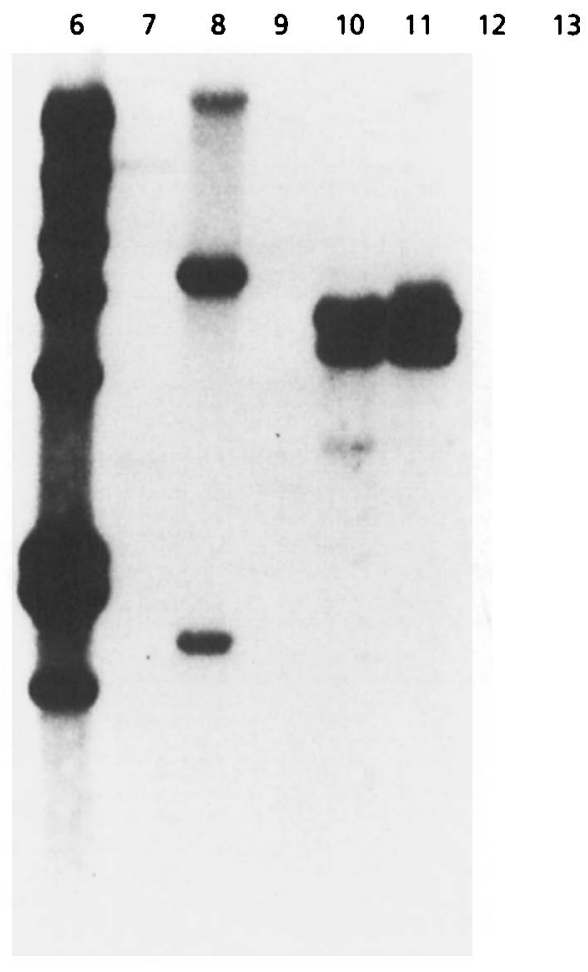

Fig. 4. $(a, b)$ Southern blot analysis of lipase genes in different strains of $C$. albicans. The yeast genomic DNA was digested with the restriction enzyme Pstl and hybridized with LIP1 DNA under (a) low-stringency and (b) high-stringency conditions. Lanes: 1, strain 36082; 2, strain 15153;3, strain 16427; 4, strain 17236; 5, strain 17737. (c) Southern blot analysis of lipase genes in different species of yeast. Lanes: $6, C$. albicans 36082; 7, C. krusei; 8, C. tropicalis; 9 , C. pseudotropicalis; 10, C. parapsilosis 1110; 11, C. parapsilosis 1112; 12, S. cerevisiae; 13, C. glabrata. The yeast genomic DNA was digested with Pstl and hybridized with LIP1 DNA. DNA isolation and Southern blot hybridization were performed as described in Methods. 
lipase, lysophospholipase and phospholipase activities by using purified substrates in a radiometric assay. Culture supernatants from $S$. cerevisiae transformed with the candidal gene were able to degrade triolein but not phosphatidylcholine nor lysophosphatidylcholine (Table 1). No hydrolytic activities against any of the substrates were observed with the control strain ( $S$. cerevisiae transformed with an empty plasmid). Table 1 shows that lipase activity was detected in concentrated filtrates from C. cylindracea. This yeast is known for its ability to produce extracellular lipases (Lotti et al., 1993) and was used as a positive control. Additionally, commercially available phospholipase (Sigma) was used as a positive control for phospholipase activity. These results indicate that the cloned candidal gene encodes a lipase.

\section{Evidence that egg yolk contains substrates for both phospholipase and lipase}

To substantiate that egg yolk contains substrates for both lipases and phospholipases, we extracted the total lipid content from one egg yolk and analysed the extracted lipids using solvent systems that resolve polar (e.g. phospholipids, the substrates for phospholipases) and non-polar (e.g. triglycerides, the substrates for lipases) lipids. Our data demonstrated that egg yolk contains, in addition to cholesterol, triglycerides, phosphatidylcholine and phosphatidylethanolamine (data not shown). This finding confirms that egg yolk contains substrates for both phospholipases and lipases.

\section{Southern blot analysis suggests that $C$. albicans may contain a LIP1 gene family, and that this gene may be present in other non-albicans species}

PstI-digested genomic DNA of five different clinical C. albicans strains was blotted on nylon membranes and hybridized at low stringency with a $1.1 \mathrm{~kb}$ oligonucleotide probe, located in the XhoI-Pst I fragment, containing the whole LIP1 gene. Between seven and eight distinct bands were identified depending on the strain tested (Fig. 4a). Two of these bands (Fig. 4b) were detected after hybridization at high stringency with the LIP1 probe, suggesting that these bands are characteristic of the LIP1 gene encoding a lipase in C. albicans. These data suggest that a lipase gene family may exist in C. albicans. The presence of two bands instead of one, following digestion with PstI, is most likely a reflection of restriction site polymorphism between the two LIP1 alleles.

In other experiments, Pst I-digested genomic DNAs of C. tropicalis, C. krusei, C. pseudotropicalis, S. cerevisiae and $C$. parapsilosis were hybridized, under low stringency, using the C. albicans LIP1 oligonucleotide probe. Three bands from C. tropicalis and C. parapsilosis and two bands from C. krusei were detected (Fig. 4c). The same PstI band pattern was found using eight C. parapsilosis strains isolated from different patients (data not shown). In contrast, no hybridization signals were observed when the C. albicans LIP1 probe

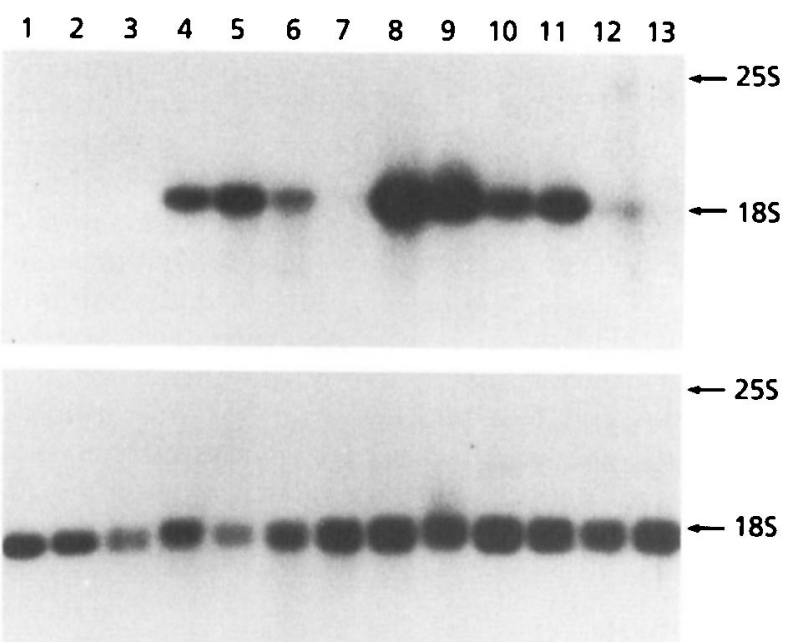

Fig. 5. Northern blot analysis of lipase mRNA levels. Various Candida species were grown in YNB supplemented with Tween 80 as sole carbon source. Lanes: 1, C. parapsilosis 1125; $2, C$. parapsilosis; 3, C. tropicalis; 4, C. albicans 16240; 5, C. albicans $16727 ; 6, C$. albicans 17336; 7, C. albicans 17737. C. albicans 36082 cells were grown in YNB supplemented with $2.5 \%$ Tween 80 (lane 8), Tween 20 (lane 9), Tween 40 (lane 10) or Tween 60 (lane 11). Expression was also monitored for this C. albicans strain following growth in YNB supplemented with either triglycerides (lane 12$)$ or $\alpha$-naphthyl palmitate $\left(20 \mu \mathrm{g} \mathrm{ml}^{-1}\right.$ ) (lane 13). RNA isolation and Northern blot hybridization were performed as described in Methods. The upper panel displays the results of hybridization with LIP1 DNA and the lower panel shows the results of hybridization with actin DNA. The positions of rRNA are marked on the right.

was used in Southern hybridization analyses with DNA fragments from C. glabrata, C. pseudotropicalis or S. cerevisiae (Fig. 4c).

\section{Expression of the LIP1 gene}

When the expression of the LIP1 gene was monitored using Northern blot analysis, it was shown that the LIP1 transcript was expressed only in YNB minimal media supplemented with Tweens $80,60,40$ and 20 as the sole carbon source (Fig. 5). This expression was observed when the cultures were grown at either 30 or $37^{\circ} \mathrm{C}$. Expression of the LIP1 transcript was also detected when C.albicans was grown in YNB supplemented with triglycerides as the only carbon source, albeit the signal detected was weaker than the signals observed when candidal cells were grown in YNB supplemented with Tweens (Fig. 5). In contrast, no expression was observed when either rich (Sabouraud Dextrose Broth, YPD) or chemically defined (YNB, Lee's) media were used to grow the yeast. Additionally, supplementing YNB with carbohydrates (including glucose, maltose or galactose), phosphatidylcholine, $\alpha$-naphthyl palmitate, $\mathrm{K}_{2} \mathrm{HPO}_{4}$ or $\mathrm{K}_{2} \mathrm{HPO}_{4}$ plus $\mathrm{KCl}$ did not induce expression of the LIP1 transcript (data not shown). Furthermore, altering the $\mathrm{pH}$ and the temperature of incubation for cells grown in Lee's medium, supplemented with glucose $(1.25 \%, \mathrm{v} / \mathrm{v})$, did not induce the expression of the LIP1 gene (data not shown). 
To determine whether the cloned lipase gene is expressed in other C. albicans and non-albicans species, total RNA was isolated from yeast cells grown in YNB supplemented with $2.5 \%$ Tween 80 as the sole source of carbon. A single $1.7 \mathrm{~kb}$ transcript that hybridized to the LIP1 gene was detected in four clinical C. albicans isolates. However, no signal was detected in one clinical C. albicans isolate (Fig. 5). Interestingly, although significant hybridization was observed with Southern blot hybridization using DNA fragments from $C$. parapsilosis and C. tropicalis (Fig. 4c), indicating that homologous sequences were present, we were unable to detect a lipase expression signal from these non-albicans species grown under these conditions (Fig. 5).

\section{DISCUSSION}

A gene encoding a candidal lipase was cloned by complementation in S. cerevisiae. Comparison of the predicted protein sequence of the candidal lipase revealed significant homology with the lipid-binding site of lipases from C. cylindracea and Candida antarctica (Uppenberg et al., 1994), and other fungi, such as $G$. candidum (Sidebottom et al., 1991). There was also significant homology with the lipid-binding region of mammalian lipases (Lowe et al., 1989) (Fig. 3). The conserved residues of this lipid-binding site include Gly$\mathrm{X}$-Ser-X-Gly. The serine of the active site has been shown to be enclosed in this highly conserved domain (Lotti et al., 1993). This consensus domain represents the only feature shared by all determined lipase sequences (Antonian, 1988) including those from C. cylindracea and $G$. candidum. The remainder of the lipase structure is very heterogeneous from species to species.

Lipase genes cloned from C.cylindracea encode proteins of approximately $57 \mathrm{kDa}$ and 534 amino acids (Lotti $e t$ al., 1993). These enzymes are larger than the cloned $C$. albicans lipase that we have identified. The deduced sequence of the lipase from $C$. albicans cloned in this study contained five potential $\mathrm{N}$-glycosylation sites. Previously identified lipases have had one to five potential N-glycosylation sites (Lotti et al., 1993; Uppenberg et al., 1994). Additionally, the lipase from C. albicans contained nine cysteine residues, while other cloned lipases contain between five and nine cysteine residues (Lotti et al., 1993; Uppenberg et al., 1994).

Our Southern hybridization findings suggest that $C$. albicans may contain a LIP gene family. This is expected since lipase gene families have been reported for other Candida spp.; for example, C. cylindracea is known to contain five distinct lipase genes (Lotti et al., 1993).

In this study, detection of mRNA levels specific for a LIP1 gene was only possible under a limited set of conditions. The presence of either a Tween compound or a triglyceride, and the lack of a carbohydrate source were found to be critical for the expression of this gene. Tweens are water-soluble mixtures of polyoxyethylenesorbitan compounds containing different types of fatty acids. Fatty acids incorporated in Tweens are: oleate in Tween 80, stearate in Tween 60, palmitate in Tween 40 and laurate in Tween 20. Our results showed that the lipase gene is expressed in cells grown in YNB supplemented with any of the Tween species, irrespective of the carbon chain length or degree of saturation. Thus, the expression is not dependent on the number of carbons or double bonds making up the fatty acids incorporated. The difference in expression signal observed between cells grown in the presence of Tween or triglycerides, the latter inducing a relatively weaker level of expression, could be due to the difference in solubility between these compounds. The poor solubility of triglycerides may have provided limited availability to C. albicans. The fact that carbohydrate supplementation inhibited LIP1 expression is not entirely surprising as glucose is known to repress the transcription of a number of genes in Saccharomyces, including FOX1 which encodes acyl-CoA oxidase, involved in the $\beta$ oxidation of fatty acids (Stanway et al., 1995). Also, growth media containing low levels of glucose have been shown to induce increased activity of the SNF1 product, a protein kinase responsible for the derepression of many glucose-repressed genes. SNF1 is also known to inactivate a key enzyme (acetyl-CoA carboxylase) involved in fatty acid biosynthesis (Woods et al., 1994). Interestingly, we found that the presence of glucose represses LIP1 expression. This finding is in contrast with our observations regarding PLB1, a gene encoding candidal extracellular phospholipase B, where maximum expression was observed in medium containing a high concentration of glucose (Ibrahim et al., 1996). These findings suggest that these two genes are expressed under different environmental conditions which may reflect different biological functions of these enzymes.

The LIP1 gene from C. albicans was identified by screening transformed $S$. cerevisiae for clones that produced a precipitate when grown on egg-yolk medium. This medium has predominantly been used to screen for the production of extracellular phospholipase (Price et al., 1982; Samaranayake et al., 1984; Williamson et al., 1986). Additionally, we discovered that egg yolk contains substantial amounts of triglycerides as well as phospholipids. The fact that eggyolk medium cannot distinguish between the secretion of lipase and phospholipase activity represents an important finding originating from this study.

The specific role of lipases in the pathogenesis of candidal infections is unknown and has received limited attention. We are aware of only one study attempting to find a correlation between pathogenicity of Candida species and production of lipases. These authors reported that candidal species considered to be more pathogenic had higher levels of lipase activity compared to less pathogenic ones (Ogawa et al., 1992). To determine the contribution of lipases to candidal virulence with greater certainty, it is necessary to use targeted distuption to delete the lipase gene. Our cloning and future disruption of the lipase gene should contribute to our understanding of the role of these enzymes 
in candidal pathogenesis. These studies are currently underway.

\section{ACKNOWLEDGEMENTS}

This work was supported in part by NIH grant no. 1RO1AI35097 and a grant (no. 94-S-0598) from Roerig-Pfizer Pharmaceuticals. The authors thank Steven Leidich, S. Filler and J. E. Edwards for useful discussion. This work was presented in part at the 33rd Interscience Conference on Antimicrobial Agents and Chemotherapy, October 1994, Orlando, Florida.

\section{REFERENCES}

Altschul, S. F., Gish, W., Miller, W., Myers, E. W. \& Lipman, D. J. (1990). Basic local alignment search tool. J Mol Biol 215, 403-410. Antonian, E. (1988). Recent advances in the purification, characterization and structure determination of lipases. Lipids 23, 1101-1106.

Barrett-Bee, K., Hayes, Y., Wilson, R. G. \& Ryley, J. F. (1985). A comparison of phospholipase activity, cellular adherence and pathogenicity of yeasts. J Gen Microbiol 131, 1217-1221.

Devereux, J., Haeberli, P. \& Smithies, O. (1984). A comprehensive set of sequence analysis programs for the VAX. Nucleic Acids Res $12,387-395$.

Folch, J., Lees, M. \& Sloane Stanley, G. H. (1957). A simple method for the isolation and purification of total lipids from animal tissues. J Biol Chem 226, 497-509.

Fuchs, R. (1994). Predicting protein function: a versatile tool for the Apple Macintosh. CABIOS 10, 171-178.

Ghannoum, M. A., Janini, G., Khamis, L. \& Radwan, S. S. (1986a). Dimorphism-associated variations in the lipid composition of Candida albicans. J Gen Microbiol 132, 2367-2375.

Ghannoum, M. A., Burns, G. R., Abu Elteen, K. S. \& Radwan, S. (1986b). Experimental evidence for the role of lipids in adherence of Candida spp. to human buccal epithelial cells. Infect Immun 54, 189-193.

Ghannoum, M. A., Edwards, K. E. \& Edwards, J. E., Jr (1995). Pathogenesis of fungal infections. In Baillière's Clinical Infectious Diseases, vol. 2, no. 1, pp. 1-16. Edited by F. Meunier. London: Baillière Tindall.

Hanahan, D. (1983). Studies on transformation of Escherichia coli with plasmids. $J \mathrm{Mol}$ Biol 166, 557-580.

von Heijne, G. (1986). A new method for predicting signal sequence cleavage sites. Nucleic Acids Res 14, 4683-4690.

Henikoff, S. (1984). Unidirectional digestion with exonuclease III creates targeted breakpoints for DNA sequencing. Gene 28, 351-359.

Henikoff, S. \& Henikoff, J. G. (1991). Automated assembly of protein blocks for database searching. Nucleic Acids Res 19, 6565-6572.

Ibrahim, A. S., Mirbod, F. S., Filler, G., Banno, Y., Cole, G. T., Kitajima, Y., Edwards, J. E., Jr, Nozawa, Y. \& Ghannoum, M. A. (1995). Evidence implicating phospholipase as a virulence factor of Candida albicans. Infect Immun 63, 1993-1998.

Ibrahim, A. S., Fu, Y., Fonzi, W., Zhou, X., Mirbod, F., Nakashima, S., Nozawa, Y. \& Ghannoum, M. A. (1996). Cloning, and expression of Candida albicans extracellular phospholipase B. In Abstracts of the 34th Infectious Diseases Society of America Meeting, abstract 220. New Orleans.
Jenkinson, H. F., Schep, G. P. \& Shepherd, M. G. (1988). Cloning and expression of the 3-isopropylmalate dehydrogenase gene from Candida albicans. FEMS Microbiol Lett 46, 285.

Lawrence, C. E., Altschul, S. F., Boguski, M. S., Liu, J. S., Neuwald, A. F. \& Wootton, J. C. (1993). Detecting subtle sequence signals : a Gibbs sampling strategy for multiple alignment. Science 262, 208-214.

Lee, K. L., Buckley, M. R. \& Campbell, C. (1975). An amino acid liquid synthetic medium for development of mycelial and yeast forms of Candida albicans. Sabouraudia 13, 148-153.

Lee, K. S., Patton, J. L., Fido, M., Hines, L. K., Kohlwein, S. D., Paltauf, F., Henry, S. A. \& Levin, D. E. (1994). The Saccharomyces cerevisiae PLB1 gene encodes a protein required for lysophospholipase and phospholipase B activity. J Biol Chem 269, 19725-19730.

Lotti, M., Grandori, R., Fusetti, F., Longhi, S., Brocca, S., Tramontano, A. \& Alberghina, L. (1993). Cloning and analysis of Candida cylindracea lipase sequences. Gene 124, 45-55.

Lowe, M. E., Rosenblum, J. L. \& Strauss, A. W. (1989). Cloning and characterization of human pancreatic lipase cDNA. J Biol Chem 264, 20042-20048.

Ogawa, H., Nozawa, Y., Rojanavanich, V., Tsuboi, R., Yoshiike, T., Banno, Y., Takahashi, M., Nombela, C., Herreros, E., Garcia-Saez, M. I., Santos, A. I. \& Sanchez, M. (1992). Fungal enzymes in the pathogenesis of fungal infections. $J$ Med Vet Mycol 30 S1, 189-196.

Pearson, W. R. \& Lipman, D. J. (1988). Improved tools for biological sequence comparison. Proc Natl Acad Sci USA 85, 2444-2448.

Price, M. R., Wilkinson, I. D. \& Gentry, L. O. (1982). Plate method for the detection of phospholipase activity in Candida albicans. Sabouraudia 20, 7.

Salyers, A. A. \& Whitt, D. D. (1994). Bacterial Pathogenesis: a Molecular Approach. Washington, DC: American Society for Microbiology.

Samaranayake, L. P., Raeside, J. M. \& MacFarlane, T. W. (1984). Factors affecting the phospholipase activity of Candida species in vitro. Sabouraucíia 22, 201.

Sambrook, J., Fritsch, E. F. \& Maniatis, T. (1989). Molecular Cloning : a Laboratory Manual, 2nd edn. Cold Spring Harbor, NY: Cold Spring Harbor Laboratory.

Sanger, F., Nicklen, S. \& Coulson, A. R. (1977). DNA sequencing with chain-terminating inhibitors. Proc Natl Acad Sci USA 74, 5463-5467.

Scherer, S. \& Stevens, D. S. (1988). A Candida albicans dispersed, repeated gene family and its epidemiological application. Proc Natl Acad Sci USA 85, 1452.

Schiestl, R. H. \& Gietz, R. D. (1989). High efficiency transformation of intact yeast cells using single strand nucleic acids as a carrier. Curr Genet 16, 339-346.

Schrag, J. D., Li, Y., Wu, S. \& Cygler, M. (1991). Ser-His-Glu triad forms the catalytic site of the lipase from Geotrichum candidum. Nature 351, 761-764.

Schrag, J. D., Winkler, F. K. \& Cygler, M. (1992). Pancreatic lipases: evolutionary intermediates in a positional change of catalytic carboxylases? J Biol Chem 267, 4300-4303.

Schuler, G. D., Altschul, S. F. \& Lipman, D. J. (1991). A workbench for multiple alignment construction and analysis. Proteins Struct Funct Genet 9, 180-190.

Sidebottom, C. M., Charton, E., Dunn, P. P. J., Mycock, G., Davies, C., Sutton, J. L., Macrae, A. R. \& Slabas, A. R. (1991). Geotrichum 
candidum produces several lipases with markedly different substrate specificities. Eur J Biochem 202, 485-491.

Stanway, C. A., Gibbs, J. M. \& Berardi, E. (1995). Expression of the FOX1 gene of Saccharomyces cerevisiae is regulated by carbon source, but not by the known glucose repression genes. Curr Genet 27, 404-408.

Uppenberg, J., Hansen, M. T., Patkar, S. \& Jones, T. A. (1994). The sequence, crystal structure determination and refinement of two crystal forms of lipase B from Candida antarctica. Structure 2, 293-308.

White, T. C. \& Agabian, N. (1995). Candida albicans secreted aspartyl proteinases: isoenzyme pattern is determined by cell type, and levels are by environmental factors. J Bacteriol 177, 5215-5221.

Williamson, M. I., Samaranayake, L. P. \& MacFarlane, T. W. (1986). Phospholipase activity as a criterion for biotyping Candida albicans. J Med Vet Mycol 24, 415-417.

Woods, A., Munday, M. R., Scott, J., Yang, X., Carlson, M. \& Carling, D. (1994). Yeast SNF1 is functionally related to mammalian AMP-activated protein kinase and regulates acetyl-coA carboxylase in vivo. J Biol Chem 269, 19509-19515.

Received 22 July 1996; revised 5 November 1996; accepted 11 November 1996. 